\title{
Obesogenic behaviors in US school children across geographic regions from 2003-2007
}

\author{
Susan B. Sisson ${ }^{1^{*}}$, Stephanie T. Broyles ${ }^{2}$, Danielle R. Brittain ${ }^{3}$, Kevin Short $^{1}$ \\ ${ }^{1}$ University of Oklahoma Health Sciences Center, Oklahoma City, USA; ${ }^{*}$ Corresponding author: susan-sisson@ouhsc.edu \\ ${ }^{2}$ Pennington Biomedical Research Center, Baton Rouge, USA; \\ ${ }^{3}$ University of Northern Colorado, Greeley, USA.
}

Received 5 May 2011; revised 14 July 2011; accepted 31 July 2011.

\section{ABSTRACT}

Background: increasing levels of obesity are likely associated with obesogenic behaviors such as physical activity (PA) and media time. Examination of regional and state differences in meeting recommendations for obesogenic behaviors would be useful for understanding concurrent variations in prevalence of childhood obesity. Therefore the purpose of this study was to analyze the prevalence of boys and girls meeting vigorous physical activity (VPA), daily media (TV/video viewing/video game playing) recommendations, and association with overweight and obesity across regions of the US between 2003 and 2007. Methods: data from the 2003 and 2007 National Survey of Children's Health ( $n=109,151 ; 55,540$ in 2003 and 53,611 in 2007; 51.3\% boys, mean (SE) age 11.5 (0.02) years) were used. Prevalence of meeting weekday media ( $\leq 2 \mathrm{hr} /$ day) and VPA ( $\geq 3$ days/week of minimum 20 minutes) recommendations were calculated. Logistic regression analyses were used to examine differences across regions, dates, sexes, and obesity status. Results: in 2007, the range for met the recommendations among regions was $74.2 \%-82.1 \%$ for VPA and $77.2 \%-83.7 \%$ for media viewing. The regions with the highest positive behavior levels were Alaska and Hawaii for VPA and both the Northeast and West regions for media viewing. In 2007 fewer children met media viewing recommendations than in $2003(78.3 \%$ versus $83.6 \%$, respectively, $p<0.0001$ ) but those meeting VPA recommendations increased $(74.6 \%$ versus $79.2 \%$, $p<0.0001$ ). In most states girls were less likely to meet VPA guidelines, and boys were less likely to meet media guidelines. The adjusted odds of being overweight or obese, in those children aged 10 years and older, were $1.13(95 \% \mathrm{Cl}: 1.05$, 1.21) for 0 - 2 days/wk of VPA versus 3 - 7 days/wk and $1.27(1.17,1.37)$ for $>2 \mathrm{hr} /$ day versus $\leq 2 \mathrm{hr} /$ day of media time. Further, the interaction between media time and VPA had a significant $(p<0.0001)$ association with being overweight or obese. Conclusions: obesogenic behaviors vary by region in the US, appear to be changing over time, and are associated overweight and obesity status, though differences between boys and girls are stable.

Keywords: Media Time; Vigorous Physical Activity; Behavioral Epidemiology; Trends; Geographic Differences

\section{INTRODUCTION}

In 2007-2008, nearly one-third (31.7\%) of children in the US were overweight or obese $\left(\geq 85^{\text {th }}\right.$ percentile for height and weight), a significant increase from previous decades $[1,2]$. The prevalence of overweight status varies across geographical regions, with higher rates in Southeastern states $(41.3 \%)$ and lower rates in the Central Rocky Mountain states (28.1\%) [3]. The differences in obesity rates across regions may reflect corresponding variation in obesogenic behaviors.

Behaviors such as physical activity (PA) [4-6] and television (TV) viewing [7-10] have been shown to have independent and combined [11-14] impacts on overweight and obesity. Examination of regional and state differences in meeting recommendations for obesogenic behaviors would be useful for understanding concurrent variations in prevalence of childhood obesity and providing support for lifestyle behavior change research and interventions [3]. Daily lifestyle behaviors such as PA and TV viewing are often used in obesity prevention strategies. Differences in PA and TV between boys and girls have been well established $[15,16]$ and may play 
critical roles in the targeted health behavior change. Recent research from Whitt-Glover [17] reports sex differences in the social-ecological correlates of PA and sedentary behaviors. With different individual, family and community variables associated with participation in obesogenic behaviors between boys and girls, interventions must be designed to address the appropriate target behaviors, policies and environmental constructs.

To examine whether children's PA, operationalized as vigorous physical activity (VPA), and TV viewing vary among regions of the US and whether these behaviors have changed, at the population level, over time, we analyzed data from the National Survey of Children's Health (NSCH). NSCH was designed to produce state and national prevalence estimates for a variety of physical, emotional, and behavioral health indicators in children 0 to 18 years of age [18]. Separate surveys were administered in a similar manner in 2003 and 2007, permitting a cross-sectional examination of changes in obesogenic behaviors over this time. The purpose of this study was to determine the prevalence of children ages 6 to 18 years old in the NSCH who achieved the recommended amount of weekly VPA and/or daily media (TV/ video viewing/video game playing). Further, we examined whether the prevalence of these behaviors varied 1) across geographic regions of the US, 2) between boys and girls, and 3) between 2003 and 2007, and 4) their association with overweight status. We hypothesize that there will be geographic, gender and survey year differences in obesogenic behaviors. Since the prevalence of obesity has been reported to be on the rise [1,2] it is logical to presume that from 2003 to 2007 changes in obesogenic behaviors would support this shift (i.e., higher daily media and lower VPA).

\section{METHODS}

Data from the 2003 and 2007 National Survey of Children's Health (NSCH) were used for this study. The $\mathrm{NSCH}$ was sponsored by the Maternal and Child Health Bureau and the National Center for Health Statistics [18-21]. Telephone interviews were conducted using computer assisted telephone interviewing technology between January 2003 and July 2004 and April 2007 and July 2008 with the parent or guardian who knew most about a specific randomly-selected child. The NSCH data are freely available online (http://www.cdc.gov/ nchs/about/major/slaits/nsch.htm) [19,20]. NCHS Research Ethics Review Board approved these procedures.

The analytic sample size for the current study was 109,151 children $(55,540$ in 2003 and 53,611 in 2007; $51.3 \%$ boys, mean (SE) age $11.5(0.02)$ years). Inclusion criteria were being six years of age or older, attending public or private school (i.e., not home-schooled or not enrolled in school), and having no missing values for variables of interest. Demographic and descriptive characteristics used as covariates included age, sex, ethnicity (Non-Hispanic White [NHW], Non-Hispanic Black [NHB], Hispanic, and other), poverty ( $\leq 100 \%, 101 \%$ $299 \%$, $\geq 300 \%$ ), family structure (two parent biological/adopted, two parent step family, single mother, other). Parent-reported body mass index (BMI) data were available only on those aged 10 and older [18] and were classified according to Center for Disease Control percentiles for overweight $\left(\geq 85^{\text {th }}\right.$ percentile) and obesity $(\geq$ $95^{\text {th }}$ percentile) [22].

There were minor changes in the questions used to query daily behaviors over time. In 2003, the daily media question was: "On an average school day, about how many hours does [child] usually watch TV, watch videos, or play video games?" In 2007, the wording of the question was revised to ask: "On an average weekday, about how many hours does [child] usually watch TV, watch videos, or play video games?" Responses were in number of hours per day in both surveys. The American Academy of Pediatrics' media recommendation of $\leq 2$ $\mathrm{hr}$ /day was used for the current analyses [23]. In both 2003 and 2007, the question on VPA was: "During the past week, on how many days did [child] exercise or participate in a physical activity for at least 20 minutes that made [him/her] sweat and breathe hard?" In 2003, some examples of activities were included along with the question, but in 2007 the list of activities was used only in case of extra explanation. Responses for the VPA question were recorded as the number of days per week. The VPA recommendation level for the current analyses was defined as $\geq 3$ days/week of at least 20 minutes of activity. We chose this criterion to be congruent with the recommendation for vigorous $\mathrm{PA}$ in the Federal Physical Activity Guidelines, which is 60 minutes per week [24].

The region of the country was recorded as Northeast, Midwest, South-Atlantic, South-Central, West, Alaska, and Hawaii. This assignment was based primarily on the four areas defined by the US Census Bureau [25]. There was a sum of 50 states plus Washington DC yielding 51 municipalities.

Data analyses were performed using logistic regression (PROC SURVEY LOGISTIC) to account for complex sampling designs and participant weights. A series of logistic regression models were used to answer whether there was regional variation in obesogenic behaviors. Since boys and girls have different patterns of VPA and media as previously reported [15,16], all analyses were conducted stratified by sex. The first model produced crude odds ratios by examining only the obesogenic behavior (i.e., media or VPA) and correlate (i.e., region of U.S.) of interest. Model 2 adjusted for 
potential confounders - age, ethnicity, sex, poverty level and survey year (2003 and 2007). The referent region was selected to be that with the highest prevalence of meeting the recommendation. For VPA, the referent was Alaska and for media, the referent was the West region. Wald Chi Square tests generated were used to determine if obesogenic behaviors varied across regions, between 2003 and 2007, and between boys and girls, and if there was a year-by-sex interaction. To examine the association of these obesogenic behaviors with weight status, adjusted odds of being overweight or obese were calculated for those 10 years and older (BMI was only available for $10-18$ year olds; total $n=75,427,2003 n=$ $38,081,2007 n=37,346$ ) for the interaction between media time and VPA for each state. Additionally, adjusted prevalence of combined overweight and obesity was calculated. SAS 9.2 software and procedures were used with weights and complex study design strata and cluster variables provided by NSCH.

To geographically examine the relationship between the prevalence of meeting media or VPA recommendations and whether or not that prevalence changed from 2003 to 2007 , each state was classified discretely into one of six categories by subtracting the 2003 prevalence from the 2007 prevalence. A high or low prevalence of meeting media and VPA recommendations in 2007 was defined by being above or below the median prevalence for each behavior. Having a stable prevalence from 2003 to 2007 was defined as being within two percentage points, while increasing or decreasing prevalence was defined as a change of more than two percentage points. Each discrete category of high or low prevalence and change from 2003 to 2007 was calculated for boys and girls and media and VPA separately and integrated with ArcGIS to create four maps that present each state's prevalence of obesogenic behavior and how that behavior has changed from 2003 to 2007.

\section{RESULTS}

Descriptive characteristics of the total sample for 2003 and 2007 are available in Table 1. The prevalence of children in the U.S. meeting the American Academy of Pediatrics recommendations for media time $(\leq 2$ $\mathrm{hr} /$ day) on weekdays was $80.9 \%$ for the combined sample, and decreased from $83.6 \%$ in 2003 to $78.3 \%$ in 2007 ( $p<0.0001$; Figure 1). For VPA, $76.9 \%$ of the combined sample met the recommendation ( $\geq 3$ days/week of minimum 20 minutes of vigorous activity), although this prevalence increased from $74.6 \%$ in 2003 to $79.2 \%$ in 2007 ( $p<0.0001$; Figure 1). When meeting VPA and media recommendations were combined for 2007 , $63.7 \%$ of children met both media and VPA recommenddations while $6.2 \%$ met neither. Approximately $16 \%$ met
Table 1. Descriptive characteristics of the combined sample, 2003 survey and 2007 survey for children aged $6-18$ in the National Survey of Children's Health.

\begin{tabular}{|c|c|c|c|}
\hline Variable & $\begin{array}{l}\text { Total Sample } \\
(n=109,151)\end{array}$ & $\begin{array}{c}2003 \text { only } \\
(n=55,540)\end{array}$ & $\begin{array}{c}2007 \text { only } \\
(n=53,611)\end{array}$ \\
\hline Age yr (SE) & $11.5(0.02)$ & $11.5(0.02)$ & $11.6(0.04)$ \\
\hline Male (\%) & 51.3 & 51.4 & 51.3 \\
\hline \multicolumn{4}{|l|}{ Ethnicity (\%) } \\
\hline NHW & 66.1 & 69.4 & 63.0 \\
\hline NHB & 15.6 & 14.9 & 16.2 \\
\hline Hispanic & 9.9 & 8.1 & 11.7 \\
\hline Other & 8.4 & 7.6 & 9.1 \\
\hline \multicolumn{4}{|l|}{ Poverty level (\%) } \\
\hline$<100 \%$ & 13.9 & 13.4 & 14.4 \\
\hline $100 \%-299 \%$ & 38.2 & 38.8 & 37.6 \\
\hline$\geq 300 \%$ & 47.9 & 47.8 & 48.0 \\
\hline \multicolumn{4}{|l|}{ Family structure (\%) } \\
\hline $\begin{array}{l}2 \text { biological or adop- } \\
\text { tive parents }\end{array}$ & 60.8 & 58.7 & 62.7 \\
\hline $\begin{array}{l}2 \text { parent-blended } \\
\text { families }\end{array}$ & 11.6 & 12.4 & 10.7 \\
\hline Single parent & 21.7 & 23.9 & 19.6 \\
\hline Other & 6.0 & 5.0 & 7.0 \\
\hline \multicolumn{4}{|l|}{$\begin{array}{l}\text { Volume of media } \\
\text { per day }(\%)\end{array}$} \\
\hline None/day & 6.4 & 7.2 & 5.6 \\
\hline$<1$ hour/day & 16.1 & 16.8 & 15.4 \\
\hline$\geq 1 \mathrm{hr}$ and $\leq 2 \mathrm{hr} /$ day & 58.4 & 59.6 & 57.2 \\
\hline$>2 \mathrm{hr} /$ day & 19.1 & 16.4 & 21.7 \\
\hline \multicolumn{4}{|l|}{$\begin{array}{l}\text { Meeting media } \\
\text { recommendation (\%) }\end{array}$} \\
\hline$\leq 2 \mathrm{hr} /$ day (yes) & 80.9 & 83.6 & 78.3 \\
\hline$>2$ hr/day (no) & 19.1 & 16.4 & 21.7 \\
\hline $\begin{array}{c}\text { Child has rules about } \\
\text { TV }(\%)\end{array}$ & 86.3 & 86.1 & 86.6 \\
\hline \multicolumn{4}{|l|}{$\begin{array}{l}\text { Vigorous physical } \\
\text { activity per week (\%) }\end{array}$} \\
\hline $0-1$ days/week & 13.4 & 14.9 & 12.0 \\
\hline 2 - 3 days/week & 23.5 & 25.2 & 21.9 \\
\hline 4 - 5 days/week & 29.3 & 29.3 & 29.4 \\
\hline 6 - 7 days/week & 33.8 & 30.7 & 36.7 \\
\hline \multicolumn{4}{|l|}{$\begin{array}{l}\text { Meeting Vigorous } \\
\text { physical activity } \\
\text { recommendation (\%) }\end{array}$} \\
\hline 0 - 2 days/week (no) & 23.1 & 25.4 & 20. 9 \\
\hline 3 - 7 days/week (yes) & 76.9 & 74.6 & 79.2 \\
\hline
\end{tabular}

the VPA recommendations but not the media and $15 \%$ met the media recommendations but not the VPA.

The prevalence of children meeting VPA and media recommendations ranged from $74.2 \%-82.1 \%$ and $77.2 \%-83.7 \%$, respectively, across regions of the country (Table 2). Table 2 also contains the prevalence estimates and odds ratios (95\% confidence intervals) for the crude and adjusted (age, ethnicity, sex, poverty level, survey year) logistic regression models for each region of the US for both obesogenic behaviors. For VPA, at the population level (Model 1), Midwest (OR; 95\% CI; 0.76; 0.65 - 0.88), Northeast (0.63; $0.54-0.73)$, South Atlantic $(0.70 ; 0.60,0.81)$, South Central $(0.76 ; 0.65,0.89)$, and West regions $(0.79 ; 0.67,0.94)$ had a lower likelihood of meeting recommendations of being active for at least 20 minutes $\geq 3$ days per week compared with Alaska 


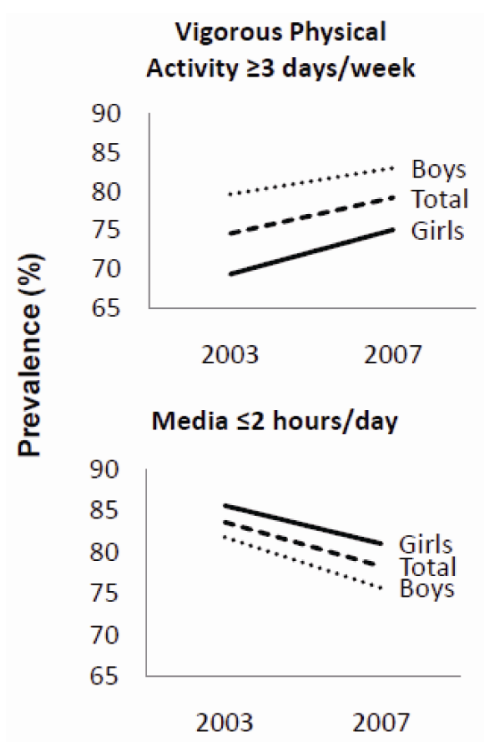

Figure 1. Prevalence of meeting media and activity recommendation by gender in 2003 and 2007.

Table 2. Prevalence estimates and odds ratios for meeting vigorous physical activity $(\geq 3$ day/wk) and media ( $\leq 2 \mathrm{hr} /$ day) recommendations by region of the US for children.

\begin{tabular}{|c|c|c|c|}
\hline Variables & $\begin{array}{c}\text { Prevalence } \\
\text { Estimate }\end{array}$ & $\begin{array}{c}\text { Model 1 OR } \\
(95 \% \mathrm{CI})\end{array}$ & $\begin{array}{c}\text { Model } 2 \text { OR } \\
(95 \% \mathrm{CI})\end{array}$ \\
\hline \multicolumn{4}{|l|}{$\begin{array}{c}3-7 \text { day/wk } \\
\text { physical activity } \\
\text { Region }\end{array}$} \\
\hline Alaska & $82.1 \%$ & referent & referent \\
\hline Hawaii & $80.5 \%$ & $0.90(0.75,1.09)$ & $0.97(0.79,1.19)$ \\
\hline West & $78.4 \%$ & $0.79(0.67,0.94)^{*}$ & $0.79(0.66,0.94)^{*}$ \\
\hline South Central & $77.7 \%$ & $0.76(0.65,0.89)^{*}$ & $0.77(0.65,0.91)^{*}$ \\
\hline Midwest & $77.6 \%$ & $0.76(0.65,0.88)^{*}$ & $0.69(0.59,0.81)^{*}$ \\
\hline South Atlantic & $76.2 \%$ & $0.70(0.60,0.81)^{*}$ & $0.67(0.57,0.78)^{*}$ \\
\hline Northeast & $74.2 \%$ & $0.63(0.54,0.73)^{*}$ & $0.57(0.49,0.67)^{*}$ \\
\hline \multicolumn{4}{|l|}{$\leq 2 \mathrm{hr}$ media } \\
\hline \multicolumn{4}{|l|}{ Region } \\
\hline West & $83.7 \%$ & referent & referent \\
\hline Northeast & $83.3 \%$ & $0.97(0.85,1.11)$ & $0.98(0.85,1.11)$ \\
\hline Alaska & $83.1 \%$ & $0.96(0.80,1.16)$ & $0.97(0.80,1.17)$ \\
\hline Midwest & $81.0 \%$ & $0.83(0.74,0.94)^{*}$ & $0.85(0.75,0.96)^{*}$ \\
\hline Hawaii & $80.9 \%$ & $0.83(0.69,0.99)^{*}$ & $0.84(0.69,1.02)$ \\
\hline South Atlantic & $78.9 \%$ & $0.73(0.64,0.83)^{*}$ & $0.88(0.77,1.01)$ \\
\hline South Central & $77.2 \%$ & $0.66(0.58,0.75)^{*}$ & $0.81(0.70,0.93)^{*}$ \\
\hline
\end{tabular}

"Denotes significance. Listed in order of highest to lowest prevalence of meeting VPA or media recommendations. Model 1 includes region of country only for crude odds ratios. Model 2 includes region of country and covariates (age, ethnicity, sex, poverty level, survey year) for adjusted odds ratios. States in the West include AZ, CA, CO, ID, MT, NV, NM, OR, UT, WA, and WY; Northeast include ME, NH, VT, MA, RI, CT, NY, NJ, and PA; Midwest include IL, IN, IA, KS, MI, MN, MO, NE, ND, SD, OH, and WI; South Atlantic include FL, GA, NC, SC, VA, WV, MD, DC, and DE; South Central include AL, KY, MS, TN, AR, LA, OK and TX.

(referent). These findings were similar even after accounting for regional differences in the demographic characteristics of the children sampled (Model 2). For media, at the population level (Model 1), Midwest (0.83; 0.74 - 0.94), Hawaii $(0.83 ; 0.69-0.99)$, South Atlantic
$(0.73 ; 0.64-0.83)$ and South Central $(0.66 ; 0.58-0.75)$ regions had lower likelihood of meeting recommendations of $\leq 2 \mathrm{hr} /$ day compared to the West (referent). However, after adjusting for regional demographic differences (Model 2), only Midwest (0.85; $0.75-0.96)$ and South Central $(0.81 ; 0.70-0.93)$ had lower likelihood of meeting recommendations.

Figure 2 depicts, for each state, the 2007 prevalence of meeting media (panels A-B) and VPA recommendations (panels C-D) and change in prevalence from 2003 to 2007 for boys and girls separately. The state-by-state prevalence estimates of meeting VPA and media recommendations for boys and girls and by year are shown in Table 3 (VPA) and Table 4 (media). The prevalence of children meeting media recommendations decreased in most states (34/51 states for girls and 40/51 states for boys), while the prevalence of meeting VPA recommendations was either stable (11/51 states for girls and 19/51 states for boys) or increasing (39/51 states for girls and $31 / 51$ states for boys) from 2003 to 2007. For both survey years combined, girls were more likely than boys to meet media recommendations (i.e., boys were more likely to exceed 2 hours per day, $p<0.0001$ ). This difference between girls and boys in media time did not change over the two survey years $(p=0.59)$. In contrast, girls were less likely to meet VPA recommendations (i.e., girls were more likely to perform less than 3 days per week of VPA, $p<0.0001)$. This difference between boys versus girls in meeting VPA recommendations did not change over the two survey years $(p=0.62)$, as depicted in Figure 1.

Within individual states, the interaction between sex and survey year only reached significance for South Carolina for prevalence of meeting VPA recommendations and in Virginia for prevalence of meeting media recommendations. In South Carolina, the prevalence of meeting VPA recommendations increased from 2003 to 2007 for girls $(63.3 \%$ to $76.6 \%)$ and slightly decreased for boys $(80.2 \%$ to $79.9 \%)$. In Virginia, the prevalence of meeting media recommendations increased $(80.4 \%$ to $81.5 \%)$ for boys and decreased for girls $(86.3 \%$ to $77.4 \%$ ). There were no significant interactions between sex and survey year within any of the national regions.

The adjusted odds of being overweight or obese, in those children aged 10 years and older, were $1.13(95 \%$ CI: $1.05,1.21)$ for 0 - 2 days/wk of VPA versus 3 - 7 days/wk and 1.27 (95\% CI: 1.17,1.37) for $>2 \mathrm{hr} /$ day versus $\leq 2 \mathrm{hr} /$ day of media time. Prevalence of overweight and obesity is presented along state-by-state obesogenic behaviors in Table 3. Further, the interaction between media time and VPA had a significant $(\beta=0.40 \pm 0.06$ SE, $\left.\chi^{2}=39.95, p<0.0001\right)$ association with being overweight or obese for the nation. When each state was 

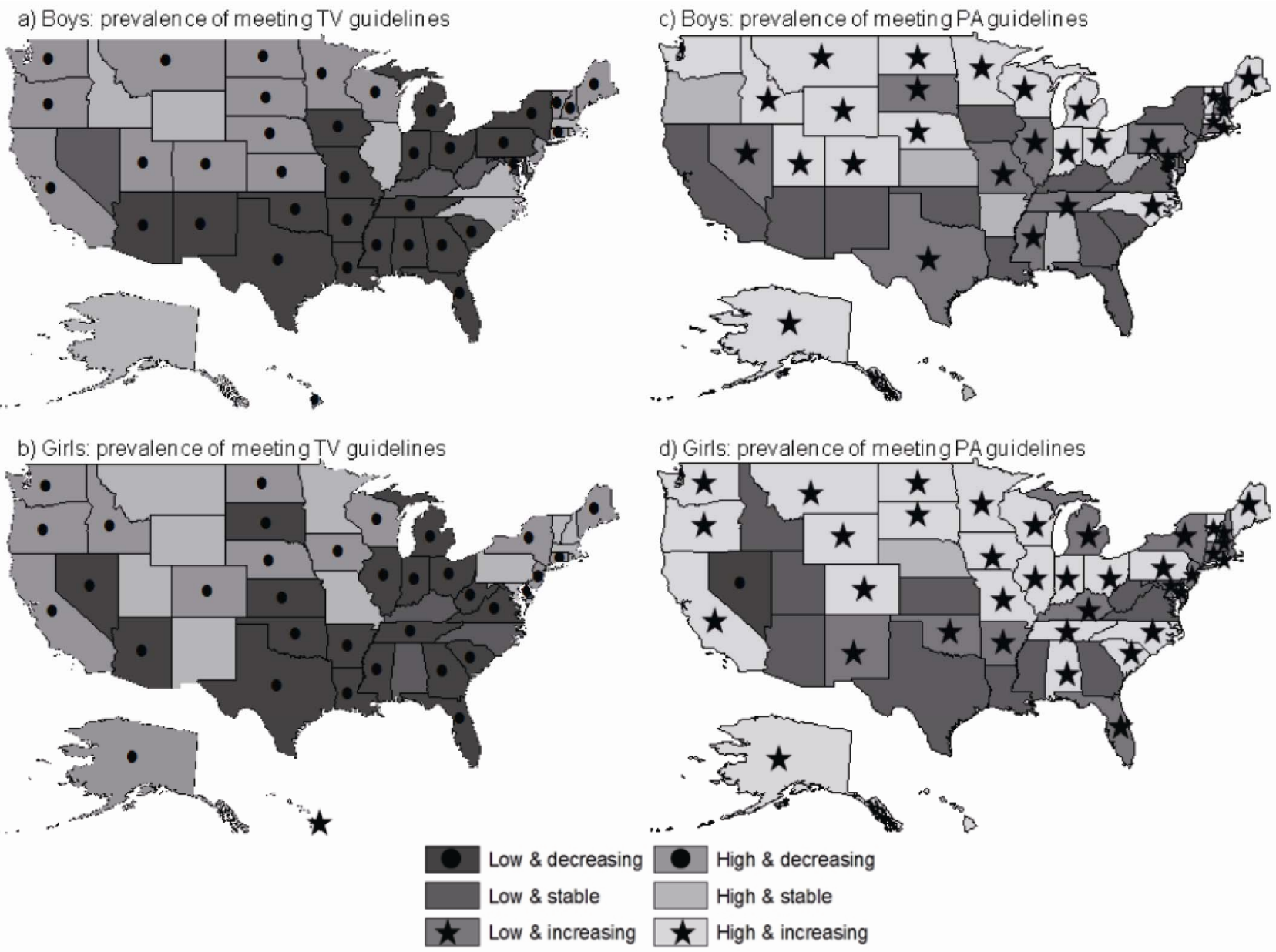

Figure 2. Change in meeting media and vigorous physical activity recommendations in boys (A\&C) and girls (B\&D) from 20032007.

examined individually, 13 of the 51 states had a significant interaction between media and VPA on overweight and obesity status; available for relevant states in Table 5.

\section{DISCUSSION}

The primary finding of this study was that there are regional and gender differences in the prevalence of meeting VPA ( $\geq 3$ days/week of minimum 20 minutes) and media ( $\leq 2 \mathrm{hr} /$ day) recommendations in children aged 6 to 18 years in the US Girls were more likely to meet the media recommendation but not VPA. Furthermore, there were changes in the prevalence of meeting media and VPA recommendations between survey years 2003 and 2007. Generally, the prevalence of meeting VPA recommendations was stable or increased while the prevalence of meeting media recommendations decreased. Obesogenic behaviors were also significantly associated with overweight status for the nation as a whole and for some individual states.

These obesogenic behaviors individually and combined were associated with overweight status for the nation as a whole and for some states, but not every individual state. These findings support some, $[10,11,13]$ but not all, previous studies [26]. The regional differences in obesogenic behaviors shown in the present study may partially explain the geographic variations in children's overweight status; states that have a higher prevalence of meeting recommendations may have lower levels of overweight and obesity [3]. For example, in $200769 \%$ boys in Mississippi, met TV viewing and $81 \%$ met VPA recommendations concurrent prevalence of overweight of obesity was $45.1 \%$ (approximately $15 \%$ higher than the national average). In $2007,85 \%$ of boys in Vermont met media and $87 \%$ met VPA recommendations. Concurrent prevalence of overweight and obesity was $25.1 \%$ (approximately $6 \%$ lower than national average). These data are examples of the geographic disparities in obesogenic behavior associated with over- 
Table 3. Prevalence estimates of meeting vigorous physical activity recommendations by state for $2003 \& 2007$.

\begin{tabular}{|c|c|c|c|c|c|}
\hline & 2007 & 2007 & & 2003 & \\
\hline & Prevalence & $\geq 3$ day $/ w k$ & & $\geq 3$ day/wk & \\
\hline & & Vigorous & & Vigorous & \\
\hline & Uverweight & Physical & & Physical & \\
\hline & & Activity & & Activity & \\
\hline State & Obesity & Boys & Girls & Boys & Girls \\
\hline United States & 30.8 & 83.0 & $75.1^{\mathrm{a}}$ & 79.6 & $69.4^{\mathrm{a}}$ \\
\hline Alaska & 34.2 & 90.1 & $82.7^{\mathrm{a}}$ & 79.8 & $75.4^{\mathrm{a}}$ \\
\hline Alabama & 36.5 & 86.8 & $79.4^{b}$ & 85.4 & $76.3^{b}$ \\
\hline Arkansas & 36.5 & 85.2 & $72.5^{\mathrm{a}}$ & 83.6 & $67.3^{\mathrm{a}}$ \\
\hline Arizona & 27.8 & 79.4 & $72.0^{\mathrm{a}}$ & 80.1 & $73.0^{b}$ \\
\hline California & 26.9 & 81.7 & 77.3 & 81.2 & 75.2 \\
\hline Colorado & 25.2 & 86.0 & $75.8^{\mathrm{a}}$ & 79.4 & $72.3^{b}$ \\
\hline Connecticut & 26.4 & 81.8 & $70.7^{\mathrm{a}}$ & 75.7 & $65.7^{\mathrm{a}}$ \\
\hline $\begin{array}{c}\text { Washington, } \\
\text { DC }\end{array}$ & 35.1 & 72.7 & $64.5^{\mathrm{a}}$ & 75.9 & $59.3^{\mathrm{a}}$ \\
\hline Delaware & 31.7 & 79.3 & $69.9^{\mathrm{a}}$ & 77.3 & $64.0^{\mathrm{a}}$ \\
\hline Florida & 33.3 & 81.1 & $70.8^{\mathrm{b}}$ & 81.5 & $67.9^{\mathrm{a}}$ \\
\hline Georgia & 35.4 & 82.5 & $70.1^{\mathrm{a}}$ & 82.2 & $69.0^{\mathrm{a}}$ \\
\hline Hawaii & 28.2 & 84.9 & $82.2^{\mathrm{a}}$ & 82.9 & $71.8^{\mathrm{a}}$ \\
\hline Iowa & 26.6 & 82.5 & 76.6 & 82.5 & $71.5^{\mathrm{a}}$ \\
\hline Idaho & 27.4 & 83.8 & $74.7^{\mathrm{a}}$ & 75.8 & 73.4 \\
\hline Illinois & 35.4 & 81.7 & 76.5 & 77.7 & $69.9^{b}$ \\
\hline Indiana & 29.2 & 84.9 & $76.6^{b}$ & 75.7 & 70.5 \\
\hline Kansas & 32.0 & 84.7 & $74.5^{\mathrm{a}}$ & 83.9 & $75.4^{\mathrm{a}}$ \\
\hline Kentucky & 36.2 & 78.6 & 72.8 & 79.4 & $66.2^{\mathrm{a}}$ \\
\hline Louisiana & 36.6 & 83.4 & $73.3^{\mathrm{a}}$ & 82.4 & $73.3^{\mathrm{a}}$ \\
\hline Massachusetts & 31.0 & 84.7 & $74.8^{\mathrm{a}}$ & 76.0 & $67.5^{\mathrm{a}}$ \\
\hline Maryland & 29.2 & 81.5 & 74.6 & 73.4 & $62.3^{\mathrm{a}}$ \\
\hline Maine & 28.5 & 85.1 & 82.3 & 77.2 & $68.4^{\mathrm{a}}$ \\
\hline Michigan & 30.4 & 83.7 & $74.1^{\mathrm{a}}$ & 78.4 & 65.0 \\
\hline Minnesota & 21.5 & 88.9 & $79.8^{a}$ & 79.9 & 74.4 \\
\hline Missouri & 30.5 & 83.4 & 80.4 & 80.5 & $72.4^{\mathrm{a}}$ \\
\hline Mississippi & 45.1 & 81.7 & $70.5^{\mathrm{a}}$ & 78.0 & $70.5^{b}$ \\
\hline Montana & 25.4 & 84.6 & 82.1 & 81.4 & 76.2 \\
\hline North Carolina & 33.9 & 86.2 & 80.4 & 82.3 & $70.1^{\mathrm{a}}$ \\
\hline North Dakota & 26.5 & 87.0 & $79.1^{\mathrm{a}}$ & 81.5 & $74.7^{\mathrm{b}}$ \\
\hline Nebraska & 30.5 & 87.6 & $76.6^{\mathrm{a}}$ & 81.2 & 75.7 \\
\hline New Hampshire & 29.8 & 82.7 & $75.3^{b}$ & 76.0 & $65.5^{\mathrm{a}}$ \\
\hline New Jersey & 31.8 & 82.5 & 75.1 & 77.6 & $58.7^{\mathrm{a}}$ \\
\hline New Mexico & 32.5 & 78.5 & 74.0 & 80.0 & $66.1^{\mathrm{a}}$ \\
\hline Nevada & 31.4 & 82.3 & $71.8^{\mathrm{b}}$ & 79.8 & 74.3 \\
\hline New York & 32.7 & 79.9 & $72.3^{b}$ & 78.7 & $61.4^{\mathrm{a}}$ \\
\hline Ohio & 33.2 & 86.2 & $75.8^{\mathrm{a}}$ & 77.6 & $66.3^{\mathrm{a}}$ \\
\hline Oklahoma & 39.6 & 83.2 & $75.3^{b}$ & 83.6 & $70.6^{\mathrm{a}}$ \\
\hline Oregon & 23.0 & 83.9 & 79.6 & 83.1 & $77.2^{b}$ \\
\hline Pennsylvania & 28.0 & 82.1 & 76.9 & 75.8 & $63.2^{\mathrm{a}}$ \\
\hline Rhode Island & 25.9 & 84.2 & $76.7^{\mathrm{a}}$ & 70.3 & 64.4 \\
\hline South Carolina & 32.7 & 79.9 & 76.6 & 80.2 & $63.3^{\mathrm{a}}$ \\
\hline South Dakota & 27.7 & 82.3 & 76.7 & 77.3 & $69.6^{\mathrm{b}}$ \\
\hline Tennessee & 37.3 & 82.2 & 77.0 & 77.0 & $63.8^{\mathrm{a}}$ \\
\hline Texas & 29.4 & 83.3 & 74.0 & 81.0 & $74.1^{\mathrm{b}}$ \\
\hline Utah & 21.7 & 84.3 & $67.1^{\mathrm{a}}$ & 77.9 & $66.9^{\mathrm{a}}$ \\
\hline Virginia & 30.1 & 80.2 & $72.2^{b}$ & 80.8 & $71.4^{\mathrm{a}}$ \\
\hline Vermont & 25.1 & 87.4 & 82.4 & 82.7 & $69.9^{\mathrm{a}}$ \\
\hline Washington & 29.1 & 86.6 & $76.8^{\mathrm{a}}$ & 79.5 & $72.6^{b}$ \\
\hline Wisconsin & 28.2 & 87.4 & $77.6^{\mathrm{a}}$ & 79.3 & 74.9 \\
\hline West Virginia & 37.1 & 84.0 & $75.7^{\mathrm{a}}$ & 84.5 & $74.8^{\mathrm{a}}$ \\
\hline Wyoming & 25.5 & 87.0 & $80.8^{\mathrm{b}}$ & 81.6 & $73.8^{\mathrm{a}}$ \\
\hline
\end{tabular}

Sex differences (Wald Chi Square): ${ }^{\mathrm{a}} p<0.01,{ }^{\mathrm{b}} p<0.05$. The analytic sample size for each state ranged from 754 in Utah to 1326 in Missouri for 2003 and from 832 in California to 1173 in New Hampshire for 2007. The sample for calculation of prevalence of overweight and obesity was limited to those 10 years of age and older $(n=37,346$ in 2007 vs. 55,540 in 2003 and 53,611 in 2007).
Table 4. Prevalence estimates of meeting media (TV/video viewing/video game playing) recommendations by state for $2003 \& 2007$.

\begin{tabular}{|c|c|c|c|c|}
\hline & \multicolumn{2}{|c|}{2007} & \multicolumn{2}{|c|}{2003} \\
\hline & $\leq 2 \mathrm{hr} / \mathrm{c}$ & //viedo & $\leq 2 \mathrm{hr} / \mathrm{c}$ & /viedo \\
\hline State & Boys & Girls & Boys & Girls \\
\hline United States & 75.7 & $81.0^{\mathrm{a}}$ & 81.8 & $85.6^{\mathrm{a}}$ \\
\hline Alaska & 79.7 & 82.9 & 81.5 & $88.7^{\mathrm{b}}$ \\
\hline Alabama & 72.1 & 76.6 & 80.7 & 77.2 \\
\hline Arkansas & 73.3 & 74.7 & 76.4 & 82.4 \\
\hline Arizona & 75.8 & 79.8 & 83.3 & 87.2 \\
\hline California & 78.5 & 82.9 & 83.2 & 88.2 \\
\hline Colorado & 81.6 & 85.2 & 86.7 & 91.2 \\
\hline Connecticut & 81.3 & 85.2 & 87.2 & 89.4 \\
\hline Washington, DC & 70.5 & 72.9 & 76.5 & 74.1 \\
\hline Delaware & 79.7 & 79.9 & 80.1 & $85.5^{\mathrm{b}}$ \\
\hline Florida & 64.5 & $77.4^{\mathrm{b}}$ & 82.3 & 85.8 \\
\hline Georgia & 71.5 & 77.5 & 83.9 & 83.9 \\
\hline Hawaii & 77.7 & $84.4^{\mathrm{b}}$ & 80.4 & 81.5 \\
\hline Iowa & 77.2 & 82.5 & 84.1 & $89.2^{\mathrm{b}}$ \\
\hline Idaho & 85.3 & 86.5 & 87.0 & 89.4 \\
\hline Illinois & 79.2 & 79.7 & 79.2 & 84.3 \\
\hline Indiana & 74.9 & 78.7 & 79.7 & 84.8 \\
\hline Kansas & 78.6 & 78.7 & 87.4 & 87.0 \\
\hline Kentucky & 76.7 & 80.4 & 76.4 & 82.2 \\
\hline Louisiana & 69.6 & 69.6 & 73.8 & 76.0 \\
\hline Massachusetts & 81.7 & 87.0 & 82.7 & $88.1^{\mathrm{b}}$ \\
\hline Maryland & 76.2 & $85.6^{\mathrm{a}}$ & 82.4 & 85.8 \\
\hline Maine & 82.3 & 83.8 & 86.3 & $92.6^{\mathrm{a}}$ \\
\hline Michigan & 73.9 & 77.7 & 80.3 & 84.9 \\
\hline Minnesota & 83.7 & $90.5^{\mathrm{b}}$ & 88.1 & 90.6 \\
\hline Missouri & 75.4 & $85.4^{\mathrm{a}}$ & 79.1 & 83.6 \\
\hline Mississippi & 69.0 & 68.2 & 79.4 & $71.8^{\mathrm{b}}$ \\
\hline Montana & 81.7 & $89.9^{\mathrm{a}}$ & 86.3 & $91.0^{\mathrm{b}}$ \\
\hline North Carolina & 78.1 & 81.4 & 79.7 & 80.7 \\
\hline North Dakota & 81.1 & 85.5 & 87.3 & 87.7 \\
\hline Nebraska & 77.8 & $86.1^{\mathrm{b}}$ & 86.8 & 90.5 \\
\hline New Hampshire & 81.6 & $90.3^{\mathrm{a}}$ & 85.6 & 90.0 \\
\hline New Jersey & 78.1 & 83.3 & 83.9 & 85.5 \\
\hline New Mexico & 76.6 & 85.3 & 86.3 & $85.4^{\mathrm{a}}$ \\
\hline Nevada & 73.6 & 79.9 & 75.3 & 85.4 \\
\hline New York & 77.3 & 84.0 & 84.7 & 88.5 \\
\hline Ohio & 73.9 & 75.2 & 78.6 & 82.4 \\
\hline Oklahoma & 73.6 & 79.7 & 76.9 & $83.6^{\mathrm{b}}$ \\
\hline Oregon & 78.0 & $86.3^{\mathrm{b}}$ & 82.7 & $88.4^{\mathrm{b}}$ \\
\hline Pennsylvania & 73.9 & 82.7 & 79.9 & 84.0 \\
\hline Rhode Island & 84.0 & 87.5 & 85.0 & 88.3 \\
\hline South Carolina & 68.7 & $76.8^{\mathrm{b}}$ & 76.7 & 79.3 \\
\hline South Dakota & 82.6 & 81.7 & 84.8 & 87.6 \\
\hline Tennessee & 66.5 & $79.3^{\mathrm{a}}$ & 78.6 & $85.3^{\mathrm{b}}$ \\
\hline Texas & 70.8 & 80.2 & 80.8 & 84.6 \\
\hline Utah & 80.5 & $90.9^{\mathrm{a}}$ & 84.2 & $92.5^{\mathrm{a}}$ \\
\hline Virginia & 81.5 & 77.4 & 80.4 & 86.3 \\
\hline Vermont & 85.0 & 89.9 & 90.2 & 90.9 \\
\hline Washington & 79.2 & $87.4^{\mathrm{b}}$ & 85.8 & $91.1^{\mathrm{b}}$ \\
\hline Wisconsin & 81.0 & 83.2 & 86.0 & 89.1 \\
\hline West Virginia & 75.1 & 78.6 & 76.8 & $85.4^{\mathrm{a}}$ \\
\hline Wyoming & 87.2 & 88.3 & 88.0 & 88.0 \\
\hline
\end{tabular}

Sex differences (Wald Chi Square): ${ }^{\mathrm{a}} p<0.01,{ }^{\mathrm{b}} p<0.05$. The analytic sample size for each state ranged from 754 in Utah to 1326 in Missouri for 2003 and from 832 in California to 1173 in New Hampshire for 2007. The sample for calculation of prevalence of overweight and obesity was limited to those 10 years of age and older ( $n=37,346$ in 2007 vs. 55,540 in 2003 and 53,611 in 2007).

weight and obesity status. The interaction of VPA and media had a significant association with overweight and 
Table 5. Association of the interaction of VPA and media on overweight and obesity for states in 2003 \& 2007.

\begin{tabular}{ccccc}
\hline & $\begin{array}{c}\text { Parameter } \\
\text { Estimate }\end{array}$ & SE & $\chi^{2}$ & $p$ \\
\hline Alaska & 0.40 & 0.06 & 39.95 & $<0.0001$ \\
Arizona & 1.26 & 0.35 & 12.7 & $<0.001$ \\
Florida & 0.74 & 0.29 & 6.48 & 0.01 \\
Georgia & 1.00 & 0.36 & 7.47 & 0.006 \\
Idaho & 0.74 & 0.27 & 7.74 & 0.005 \\
Illinois & 0.56 & 0.27 & 4.29 & 0.04 \\
Michigan & 0.53 & 0.25 & 4.53 & 0.03 \\
Missouri & 0.62 & 0.25 & 6.06 & 0.02 \\
Mississippi & 0.90 & 0.26 & 15.9 & $<0.001$ \\
North Carolina & 0.83 & 0.27 & 9.64 & 0.02 \\
New Hampshire & 0.59 & 0.26 & 5.06 & 0.02 \\
Wisconsin & 0.78 & 0.28 & 7.51 & 0.006 \\
Wyoming & 0.71 & 0.30 & 5.54 & 0.02 \\
\hline
\end{tabular}

The sample for calculation of prevalence of overweight and obesity was limited to those 10 years of age and older. Each analysis was adjusted for age, poverty level, family structure and survey year.

obesity for several states such that as children were less active and had higher media, overweight was higher. We predict this relationship was not observed in more states due to the increase in prevalence of meeting VPA recommendations by many states.

Our findings also demonstrate a higher prevalence of meeting VPA recommendations (76.9\%) compared with the 1999-2007 Youth Risk Behavior Surveillance System (YRBSS) (64.0\%), although the YRBSS examined high school students [27] and daily VPA has been reported to decline with age during childhood and adolescence. Furthermore, there appears to be significant changes in obesogenic behaviors in children between 2003 and 2007. In the majority of individual states (31/51 states for boys and 39/51 states for girls) the percentage of children who met VPA recommendations increased, which was contrary to our original hypothesis. However, our findings support previous work by Sturm, [28] who reported that from 1981 to 1997 sports participation increased by 73 minutes/week for 3 to 12 year olds. However, findings from the YRBSS from 1999 to 2007 showed no change in VPA in high school students [27]. The age of the children sampled may impact these findings; it is possible that younger children may be more active or even improving while older children may be maintaining the same level of VPA.

Conversely, in the majority of individual states (39/51 states for boys and 34/51 states for girls) prevalence of meeting media recommendations decreased from 2003 to 2007 (i.e., more children exceeded $\geq 2 \mathrm{hr} /$ day); congruent with our original hypothesis. The prevalence of meeting media recommendations was higher in the current study than two previous national reports which ranged from $65 \%$ - 71\% [7,27]. Furthermore, Lowry et al. [27] reported an increase in the prevalence of children meeting media recommendations from 1999 to
2007 (57\% to 67\%) in a national sample of high-school students. It is plausible that age is interacting with these health behaviors since our study examined ages six to 18 while the study by Lowry et al. [27] was conducted in high school students. We also focused on differences between boys and girls in obesogenic behaviors for each state. Overall, boys were more likely to exceed media recommendations, and girls were more likely attain insufficient VPA. These findings support previous reports that boys are more physically active, but also spend more time watching TV than girls [16].

To our knowledge, state and national prevalences of participation in obesogenic behaviors have not been reported for children 6 - 18 years. A strength of this study is the nationally representative sample collected at two time points. Additionally, information on media and VPA time was collected similarly at each time point albeit with different national samples of children. There are also some limitations which need to be addressed. These data are cross-sectional so no inference about causality or temporal changes at the individual-level can be assessed. Information was self-reported by a parent proxy using questions that have not been tested for psychometric properties, rather than by the child, which may impact the accuracy of the data collected. However, parent proxy has been reported to be an acceptable measure of participation in VPA [29] and TV viewing [30] and all questions were reviewed by an expert panel [18]. Furthermore, a recent review [30] reported that only 7\% of instruments used to assess TV viewing had been tested for reliability and validity. The authors recognize the strength of well-tested and designed measures; however, the wealth of available information on this nationally representative sample of children supersedes this limitation. Another limitation maybe the wording of the survey item related to VPA which could lead to an overestimation of children meeting recommendations in the current study. The question on VPA asked whether a minimum of 20 minutes was performed per day rather than 60 minutes per day, as stated in the Federal Physical Activity Guidelines, [24] although the definition of VPA was congruent with that assessed in the YRBSS [27]. Another potential issue that could lead to the underestimation of excessive TV viewing is that time spent with media was limited to weekdays only. Children have been reported to spend $40 \%$ - 55\% more time viewing TV on weekends compared with weekdays [31].

The fact that volume of media use appears to be increasing over time is concerning, as TV viewing has a hypothesized impact on prevalence of overweight and obesity, independent of participation in VPA [10], although not all studies are in agreement [26]. In fact, a recent study reported that an exercise-to-TV viewing 
ratio of 2.5:7 hours/week was necessary to protect against developing overweight in adolescents [32]. Some recent interventions to decrease $\mathrm{TV}$ viewing in children were successful and resulted in reduced body mass index, even in the absences of an increase in moderate-to-vigorous PA $[33,34]$. The hypothesized pathways whereby TV viewing impacts overweight status are still being investigated and include 1) decreased PA, as media time may displace time that would otherwise be used for sports or other forms of active play, 2) promotion of snacking during TV time, 3) increased daily caloric consumption and consumption of fast food spurred by exposure to child-focused advertising, and 4) lowered metabolic rate during TV viewing compared to spontaneous play $[30,35]$.

In conclusion we found significant geographic differences in the prevalence of meeting VPA and media recommendations in US children and that these behaviors were associated with higher odds of overweight or obesity status. Additionally, the present study shows that the prevalence of meeting obesogenic behavior recommendations changed from 2003 to 2007. In general, more states met VPA recommendations in 2007 than in 2003 while fewer states met the media recommendations in 2007 than in 2003. Understanding state and regional prevalence and trends could be used by public health researchers and practitioners to create regionally tailored interventions and monitor progress over time. However, approaches should address the unique correlates of activity and sedentary behaviors [17]. Further work is now needed to understand why the prevalence of obesogenic behaviors is shifting and how they affect health and disease.

\section{ACKNOWLEDGEMENTS}

There was no funding for this project.

\section{Declaration of Competing Interests}

There are no conflicts of interest.

\section{Author's Contributions}

SBS was involved with the conception, design, data acquisition, analyses and interpretation of the data as well as manuscript preparation. STB was involved with the conception, design, analyses and interpretation of the data as well as manuscript preparation. KRS and DRB were involved in interpretation and presentation of data and analyses as well as manuscript preparation.

\section{REFERENCES}

[1] Ogden, C.L., Carroll, M.D., Curtin, L.R., Lamb, M.M. and Flegal, K.M. (2010) Prevalence of high body mass index in US children and adolescents, 2007-2008. The Journal of the American Medical Association, 303, 242-249. doi:10.1001/jama.2009.2012

[2] Ogden, C.L., Carroll, M.D. and Flegal, K.M. (2008) High body mass index for age among US children and adolescents, 2003-2006. The Journal of the American Medical Association, 299, 2401-2405.

doi:10.1001/jama.299.20.2401

[3] Tudor-Locke, C., et al. (2007) A geographical comparison of prevalence of overweight school-aged children: the National Survey of Children's Health 2003. Pediatrics, 120, e1043-e1050. doi:10.1542/peds.2007-0089

[4] Fulton, J.E., et al. (2009) Physical activity, energy intake, sedentary behavior, and adiposity in youth. American Journal of Preventive Medicine, 37, S40-S49. doi:10.1016/j.amepre.2009.04.010

[5] Kim, Y. and Lee, S. (2009) Physical activity and abdominal obesity in youth. Applied Physiology, Nutrition, Metabolism, 34, 571-81. doi:10.1139/H09-066

[6] Wittmeier, K.D., Mollard, R.C. and Kriellaars, D.J. (2008) Physical activity intensity and risk of overweight and adiposity in children. Obesity, 16, 415-420. doi:10.1038/oby.2007.73

[7] Fulton, J.E., et al. (2009) Television viewing, computer use, and BMI among US children and adolescents. Journal of Physical Activity \& Health, 6, S28-S35.

[8] Jackson, D.M., et al. (2009) Increased television viewing is associated with elevated body fatness but not with lower total energy expenditure in children. The American Journal of Clinical Nutrition, 89, 1031-1036. doi:10.1038/oby.2007.73

[9] Hume, C., Singh, A., Brug, J., W. Van Mechelen, W. and Chinapaw, M.(2008) Dose-response associations between screen time and overweight among youth. Internaotional Journal of Pediatric Obesity, 4, 61-64.

[10] Crespo, C.J., et al. (2001) Television watching, energy intake, and obesity in US children: Results from the Third National Health and Nutrition Examination Survey, 1988-1994. Archives of Pediatrics \& Adolescent Medicine, 155, 360-365.

[11] Sisson, S.B., et al. (2010) Screen Time, Physical Activity, and Overweight in US Youth: National Survey of Children's Health 2003. Journal of Adolescent Health, 47, 309-311. doi:10.1016/j.jadohealth.2010.02.016

[12] Eisenmann, J.C., et al. (2008) Combined influence of physical activity and television viewing on the risk of overweight in US youth. International Journal of Obesity, 32, 613-618. doi:10.1038/sj.ijo.0803800

[13] Laurson, K.R., et al. (2008) Combined influence of physical activity and screen time recommendations on childhood overweight. The Journal of Pediatrics, 153, 209-214. doi:10.1016/j.jpeds.2008.02.042

[14] Wosje, K.S., et al. (2009) Adiposity and TV viewing are related to less bone accrual in young children. The Journal of Pediatrics, 154, 79-85.e2.

[15] Sisson, S.B., et al. (2009) Profiles of sedentary behavior in children and adolescents: The US National Health and Nutrition Examination Survey, 2001-2006. International Journal of Pediatric Obesity, 4, 353-359. doi:10.3109/17477160902934777

[16] Jago, R., et al. (2005) Adolescent patterns of physical activity differences by gender, day, and time of day. American Journal of Preventive Medicine, 28, 447-452. doi:10.1016/j.amepre.2005.02.007

[17] Whitt-Glover, M.C., et al. (2009) Disparities in physical activity and sedentary behaviors among US children and adolescents: Prevalence, correlates, and intervention im- 
plications. Journal of Public Health Policy, 30, S309S334. doi:10.1057/jphp.2008.46

[18] Blumberg, S.J., et al. (2009) Design and operation of the national survey of children's health, 2007. National Center for Health Statistics, Centers for Disease Control and Prevention, Department of Health and Human Services, Hyattsville, 1-75.

[19] Child and Adolescent Health Measurement Initiative (2010) 2003 National survey of children's health. www.childhealthdata.org

[20] Child and Adolescent Health Measurement Initiative (2009) 2007 National survey of children's health. http://www.cdc.gov/nchs/slaits/nsch.htm\#2007nsch.

[21] Blumberg, S., et al. (2005) Design and operation of the National Survey of Children's Health, 2003. National Center for Health Statistics. Vital and Health Statistics, 1, $1-131$.

[22] Kuczmarski, R.J. and Flegal, K.M. (2000) Criteria for definition of overweight in transition: Background and recommendations for the United States. The American Journal of Clinical Nutrition, 72, 1074-1081.

[23] American Academy of Pediatrics (2001) American Academy of Pediatrics: Children, adolescents, and television. Pediatrics, 107, 423-426.

[24] Office of Disease Prevention and Health Promotion, US Department of Health and Human Services (2008) United States department of health and human services, physical activity guidelines for Americans, 1-61.

[25] United States Census Bureau (2000) Census regions and divisions of the United States. http://www.census.gov/geo/www/us regdiv.pdf

[26] Marshall, S.J., et al. (2004) Relationships between media use, body fatness and physical activity in children and youth: A meta-analysis. International Journal of Obesity, 28, 1238-1246. doi:10.1038/sj.ijo.0802706

[27] Lowry, R., et al. (2009) Healthy people 2010 objectives for physical activity, physical education, and television viewing among adolescents: national trends from the Youth Risk Behavior Surveillance System, 1999-2007. Journal of Physical Activity \& Health, 6, S36-S45.

[28] Sturm, R. (2005) Childhood obesity-What we can learn from existing data on societal trends, part 1. Preventing Chronic Disease, 2, A12.

[29] Dowda, M., et al. (2007) Agreement between student-reported and proxy-reported physical activity questionnaires. Pediatric Exercise Science, 19, 310-318.

[30] Bryant, M.J., et al. (2007) Measurement of television viewing in children and adolescents: A systematic review. Obesity Reviews, 8, 197-209. doi:10.1111/j.1467-789X.2006.00295.x

[31] Biddle, S.J., Gorely, T. and Marshall, S.J. (2009) Is television viewing a suitable marker of sedentary behavior in young people? Annals of Behavioral Medicine, 38, 147 153. doi:10.1007/s12160-009-9136-1

[32] Van Den Bulck, J. and Hofman, A. (2009) The Television-to-exercise ratio is a predictor of overweight in adolescents: Results from a prospective cohort study with a two year follow up. Preventive Medicine, 48, 368-371. doi:10.1016/j.ypmed.2009.02.006

[33] Robinson, T.N. (1999) Reducing children's television viewing to prevent obesity: A randomized controlled trial. The Journal of the American Medical Association, 282, 1561-1567. doi:10.1001/jama.282.16.1561

[34] Epstein, L.H., et al. (2008) A randomized trial of the effects of reducing television viewing and computer use on body mass index in young children. Archives of Pediatrics \& Adolescent Medicine, 162, 239-245. doi:10.1001/archpediatrics.2007.45

[35] Rey-Lopez, J.P., et al. (2008) Sedentary behavior and obesity development in children and adolescents. Nutrition, Metabolism and Cardiovascular Diseases, 18, 242251. doi:10.1016/j.numecd.2007.07.008 